\title{
Power Hardware In the Loop and Ancillary Service for Voltage Regulation in Low Voltage Grid
}

\author{
Solomon Oyegoke \\ O.Solomon@greenwich.ac.uk \\ Yehdego Habtay \\ Y.T.Habtay@greenwich.ac.uk \\ Faculty of Engineering and Science \\ University of Greenwich, \\ Medway, Kent, United Kingdom
}

\author{
Marios Maniatopoulos \\ mmaniato@mail.ntua.gr \\ Panos Kotsampopoulos \\ kotsa@power.ece.ntua.gr \\ School of Electrical and Computer \\ Engineering, National Technical \\ University of Athens, Greece
}

\author{
Simeon Keates \\ S.Keates@napier.ac.uk \\ School of Engineering, \\ Edinburgh Napier University, \\ Edinburgh, United Kingdom
}

\begin{abstract}
Power production via traditional generators play a major role to meet demand, however, the trend is shifting towards utilization of distributed renewable sources. Distributed Energy Resources (DER) becomes a means to support loads locally. As DERs are typically intermittent sources, there are challenges associated with the high level of penetration of these resources that are of concern to grid operators. There are also opportunities associated with this technology as the inverters connecting the DERs could support voltage regulation by performing reactive power compensation in the grid.
\end{abstract}

The concept of utilizing droop controlled DERs as reactive power resources is explored in this paper. As the active power production fluctuates with solar insolation, the spare capacity of the inverters could be employed to provide effective reactive power compensation to support the grid.

In this paper, Power Hardware in the Loop (PHIL) simulation was employed where a single-phase PV inverter hardware is operated in parallel with three other real-time simulated inverters to deliver ancillary services. The results have shown that the switching steps of the On-Load Tap changer transformer (OLTC) were reduced, thus improving overall system performance.

Keywords—DER, PHIL, Ancillary Service, Droop Control

\section{INTRODUCTION TO POWER SYSTEMS}

The conventional power system is known to be made up of complex power networks and large-scale traditional generators such as the diesel generators, nuclear or coal plants etc. that supply power to industrial, commercial or residential loads. However, the upward trend of demand for electrical energy, depletion of natural non-renewable sources and generation of electrical energy from these sources have been linked to environmental pollution [1,2].

Other crucial issues related to conventional power generation also include energy losses due to long power lines, ageing of equipment which requires huge replacement and maintenance costs; blackout in many areas due to faults $[2,3]$. The integration of renewable sources could help mitigate some of these problems though the issues associated with the intermittent nature of renewables raises concerns to grid operators.

Power system centralisation does yield clear benefits while accommodating different forms and scale. However, the complex and highly centralised control structure of the power system also poses several challenges. In generating power using centralised control system, it is necessary to have a default or fall-back mode of operation for the individual generators so that they can at least function at minimal level if the centralised controller goes out of action.

In minimising or resolving the issues mentioned above and to further improve the reliability of the conventional power system, local power generation with decentralized control system could be employed [4-5]. In meeting growing demand in developing countries and due to environmental concerns, there has been significant growth in localized generation that is not necessarily centrally controlled. These local systems with distributed generation, usually from renewable sources, and consumer loads tends toward the development of a microgrid [6,7].

The term 'microgrid' describes a power generating model that provides power to a local area with the ability to operate independently even when it is linked to a central or main grid [8-10]. A microgrid may consist of loads, storage devices, control systems, micro sources and the Point of Common Coupling (PCC) [10]. Interconnected loads, DER sources can be managed intelligently and the independent grid has the ability to operate either in parallel with an existing utility grid or in standalone mode. The efficiency is increased when the DERs are placed closer to loads as this minimises the losses in the transmission network [11].

The microgrid can be planned to meet specific requirements such as enhancement of local reliability, voltage correction, and reduction of feeder losses. The microgrid concept highlights the advantages offered by small scale distributed generators [10] and it also makes further contributions as discussed below. In terms of grid connection capabilities, the microgrid is linked to the main grid via the PCC; the integration of renewable energy sources or smaller generators gives an opportunities to participate in the energy market [12]. It should ideally include features to enable standalone modes of operation when an issue such as fault is experienced in the grid network depending on the design and type of power sources available; an effective system could also be included for the management and coordination of critical and non-critical loads during an emergency that would temporarily allocate loads based on the available generators [13-15].

Although extensive research, ideally backed by experimental work, is essential in resolving the voltage control issues, it may not be practical to perform these experiments on 
the actual power grid due to the complex nature of the system, safety concerns and the cost implications. The concept of Hardware In the Loop (HIL) may, however, provide a way forward [16-18]. HIL has been used extensively in different power system projects and analysis showing encouraging results achieved over the years [16-26].

\section{THE HARDWARE IN THE LOOP ARCHITECTURE}

Hardware In-the Loop simulation is described as an experimental approach of combining simulations together with a Hardware under Test (HUT) [16]. HIL is a relatively recent approach employed in electrical research due to the merits associated with it such as joining or looping of hardware devices with simulated circuits in a real-time simulator.

HIL simulation provides an opportunity to test different power systems in a scaled down manner and the operating scenarios such as faults, power flow, load management, power conversion can be tested in a controlled lab environment [17]. There are two forms of HIL testing: Control Hardware In-the Loop (CHIL) and Power Hardware In-the Loop (PHIL). CHIL testing involves the exchange of low level digital or analogue signals between a real-time simulator and a controller-under-test using an analogue-todigital (A/D) and a digital-to-analogue (D/A) converters between the interfaces [17]. CHIL supports testing of protection relays, power converter controllers and power quality regulators, among other

PHIL, on the other hand, involves the testing of power devices such as photovoltaic cells, induction motors, wind turbines or energy storage. An amplifier is required between the real-time simulator and the HUT to amplify the analogue signal (voltage or current) and apply it to the HUT [16]. To complete the PHIL test set up, sensors are also needed between the HUT and the real-time simulator to measure the response of the HUT and insert it in the real-time simulator. Fig. 1 below is an illustration of the CHIL and PHIL testbed setup and depicts the difference between both forms of HIL.

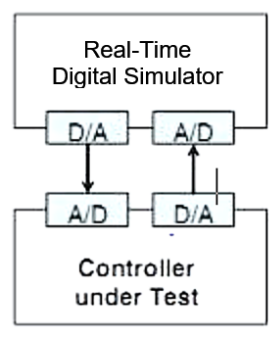

CHIL

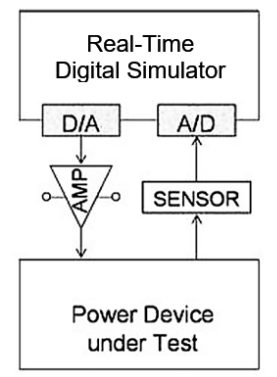

PHIL
Fig. 1: Block diagram of the CHIL and PHIL testing approach [16]

The PHIL technology can be used for extensive power system component testing which is useful in analyzing and verifying the contribution of the DER in large-scale power systems. PHIL permits more realistic conditions of testing compared to pure simulation-based work [19].
PHIL is acknowledged as standard for power system testing (IEEE P2004 recommended practice) and has been applied in power conditioning system to coordinate and improve grid frequency, and for voltage stabilization [20]. The benefit of using PHIL is the I/O capabilities available to the user to enable alteration of parameters on either the HUT or the simulated circuit in the RTDS during an experiment. Another merit of PHIL is also the scalability of the HUT [18$20]$.

On the other hand, it is important to understand the limitations of PHIL tests such as the delay between connecting devices (such as the amplifier to the HUT) causing instability issues or at cases inaccurate results [21]. If the PHIL simulation is unstable then this may cause damage to the physical hardware. Unavoidable issues such as limited converter bandwidth, sensor noise, ripple of interface amplifier may also cause instability in a PHIL simulation leading to inaccurate results [21-22]. For the PHIL testbed in this research, the HUT is a residential single-phase Photovoltaic (PV) inverter whilst the rest of the LV grid (consisting of the loads, OLTC transformer, lines, main generator etc.) circuitry was designed using the RSCAD software and simulated in the RTDS ${ }^{\circledR}$.

\section{ANCILLARY SERVICE PROVSION VIA GRID PV INVERTERS}

In providing ancillary services, the control mode can either be local, centralized or decentralized depending on various factors such as the existence of a telecommunication network, capacity, load and other grid factors. Local and centralized control are discussed below.

\section{A. Centralized vs. Local Power Control}

In designing optimum grid operation, central control could be introduced to sense the grid condition over time and intelligently dispatch real or reactive power from various generators in the grid [18]. In local control, each dispersed PV inverter generates ancillary services with no need for communication links with other PV generators inorder to obtain local measurement [27]. In this research, the different capacity of the inverters and their position in the grid network also gives an opportunity to model different droop control parameters for each inverter to achieve maximum reactive power from each inverter.

For microgrid architecture in grid-connected operation, there will be no control of the PV's active power as this is solely dependent on the solar insolation levels at this case study. The amount of reactive power supplied through the droop parameters can be limited by the inverter's apparent power due to the active power generated at any given time; there is also a minimum $\cos \varphi$, which limits the reactive power [28].

\section{B. Reactive Power dispatch using Droop Control technique}

The droop control technique is often utilised in Frequency and Voltage correction schemes. In this paper, attention is paid to reactive power compensation via droop control to establish voltage regulation. The droop control utilises measured values 
which are available locally hence it does not require any form of communication device to obtain measured values or exchange control signals [27].

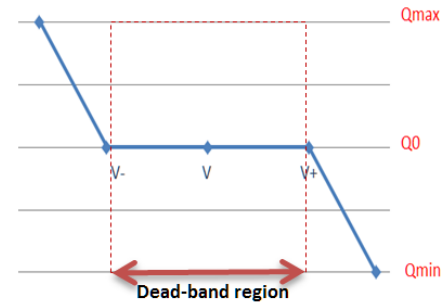

Fig. 2: The inverter's reactive power-voltage Droop Control

The voltage or $Q(U)$ droop control is shown in Fig. 2; the dead-band region is a specified value observed as ideal voltage points (usually between 0.98 and 1.02 per unit) in which the inverter does not inject or absorb reactive power unless the thresholds are exceeded. For the measured reactive power, $Q$, the voltage for the droop can be expressed as:

$$
\mathrm{V}=V_{o}+K_{Q V}\left(Q_{o}-Q\right)
$$

where $V_{o}$ is the rated voltage of the DG plant and $K_{Q V}$ is the reactive power droop coefficient; $Q_{o}$ is the reactive power dead-band threshold of the inverter.

Based on steady state performance criteria, the reactive power droop coefficients $K_{Q V}$ can be calculated by

$$
K_{Q V}=\Delta \mathrm{V} / Q_{\max }
$$

Here, $Q_{\max }$ is the maximum reactive power and $\Delta \mathrm{V}$ is the maximum voltage magnitude deviation (ideally between \pm $10 \%$ of the nominal voltage magnitude based on the EN 50160 standard) [28]. Depending on how much reactive power is needed to be injected by the inverter, the parameters of the droop can be calculated and set accordingly. The droop approach offers great flexibility, high reliability, simple structure, easy implementation and application to different power ratings [27-29]. However, at certain cases stability issues have been observed [31].

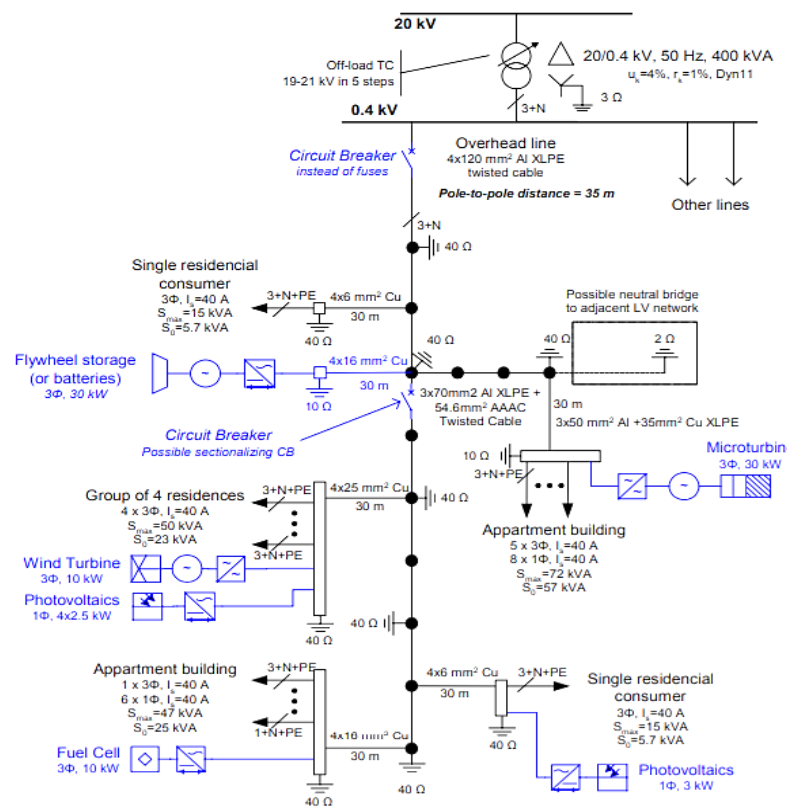

Fig 3: CIGRE Low voltage Network Benchmark [30]

\section{Network Modelling using the CIGRE Benchmark Low Voltage Microgrid}

The testbed used is a modified CIGRE low voltage residential single-phase feeder network. The actual CIGRE LV feeder benchmark in its standard form is presented with detailed analysis in [30].

In modifying the existing network in Fig. 3, an OLTC is used realize voltage control and PV inverters were used in place of all other DER sources. Various controllable loads (CL1 to CL5), which are shown in Fig. 6, were coupled to each node. The capacity of loads as required during the test, were modified using a predefined load curve typical for residential buildings as proposed by the authors in [30].

\section{PHIL EXPERIMENTAL TEST AND RESULTS}

Before setting up the PHIL testbed with the HUT device, the entire network was simulated in the RTDS ${ }^{\circledR}$ to ensure the right parameters were selected which can also safeguard the laboratory equipment from damage. This also gives an opportunity to validate simulation results against the results derived from the PHIL experimental setup shown in Fig. 6. All the DGs were PV generators; the HUT used in this paper is a $3 \mathrm{KVA}$ single phase inverter $(P V 3)$. Four cycles of testing were conducted; the results are highlighted and discussed below:

\section{i. $\quad$ Reference Testing}

In this test cycle, the LV residential grid model was examined with no voltage regulation by neither the OLTC nor the inverters' $Q(U)$ Droop controller. The attributes of the node voltage could be linked to the corresponding nodal load requirement. It can also be seen from Fig. 4 below that the secondary voltage $(V \mathrm{Sec}$ ) remains at the nominal value; the operation of the residential loads could have an impact on the voltages.

From Fig. 4, it can be seen that at the early hours of the morning and late at night that voltages are less than nominal because there is no PV production. At the point around 20:00hrs where loads are at maximum and with no solar insolation from the PV inverters to support active loads locally, the voltages are further affected. During the daytime the PV inverters could generate more power than is required by the loads that are operating at mid-levels, this also causes the voltages to rise above nominal. Though higher penetration of PVs is a concern to grid operators, the inverters of these PV systems become a tool for reactive power compensation in establishing voltage control when these scenarios happen.

In this research, the different capacity of the inverters and their position in the grid network also gives an opportunity to model different droop control parameters for each inverter to achieve maximum reactive power from each inverter. 


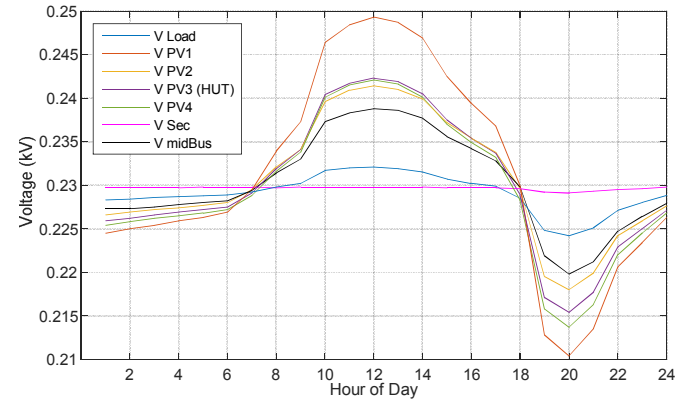

Fig. 4: Reference Testing - Node Voltages without Droop nor OLTC

\section{ii. Reactive Power via OLTC only.}

In this test cycle, the OLTC is solely in operation as the $Q(U)$ Droop functionality of all the inverters (HUT and in RTDS) was switched off. As the voltage goes beyond the set points for more than 1 second, the Automatic Voltage Control (AVC) relay of the OLTC increases or reduces the secondary voltage by altering the OLTC tap position by a step size. The step size of each tap change was set to $0.01 \mathrm{pu}(1 \%)$ of the nominal voltage.

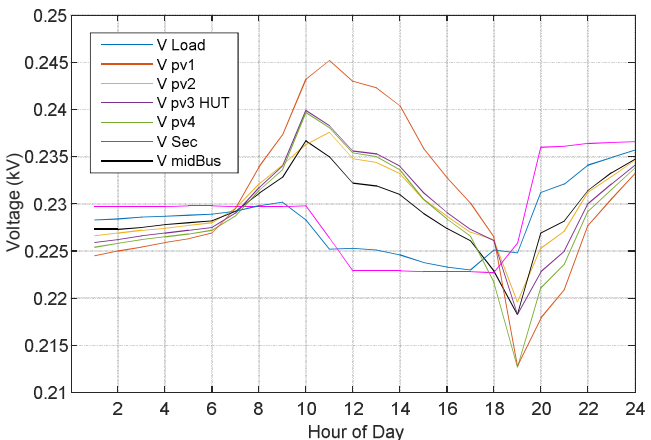

Fig. 5: Node Voltages with OLTC taps only

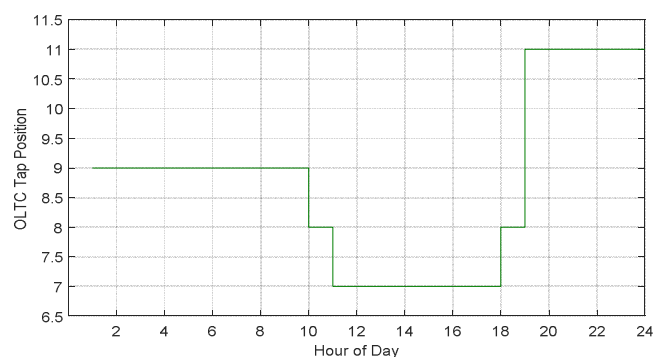

Fig. 7: OLTC Tap Position without $Q(U)$ Droop from PV inverters

Fig. 5 shows the node voltages during the time of low load consumption and how voltage control is realized when the residential loads were at peak levels; voltage control is achieved as a result of the OLTC tap switching in Fig. 7 above. Reactive power from the main grid (Qgrid) fully supports the reactive residential loads whilst the PV inverters supply active power to the active loads and the excess is fed into the main grid.

\section{iii. $\quad$ Reactive Power via $Q(U)$ Droop Controlled Inverters only.}

In this test cycle, the OLTC tap operation was deactivated to analyze the inverters' response and reactive power contribution in the network. The inverter in this case produced active power based on available solar insolation and the remaining capacity to supply or absorb reactive power as shown in Fig. 9 based on the droop parameters.

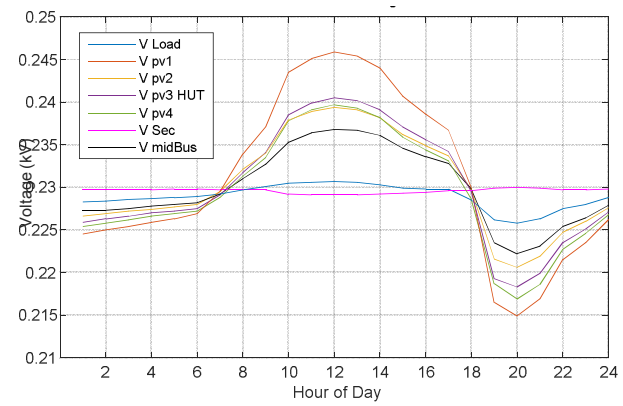

Fig. 8: Node Voltages with PV Inverter Droop control only

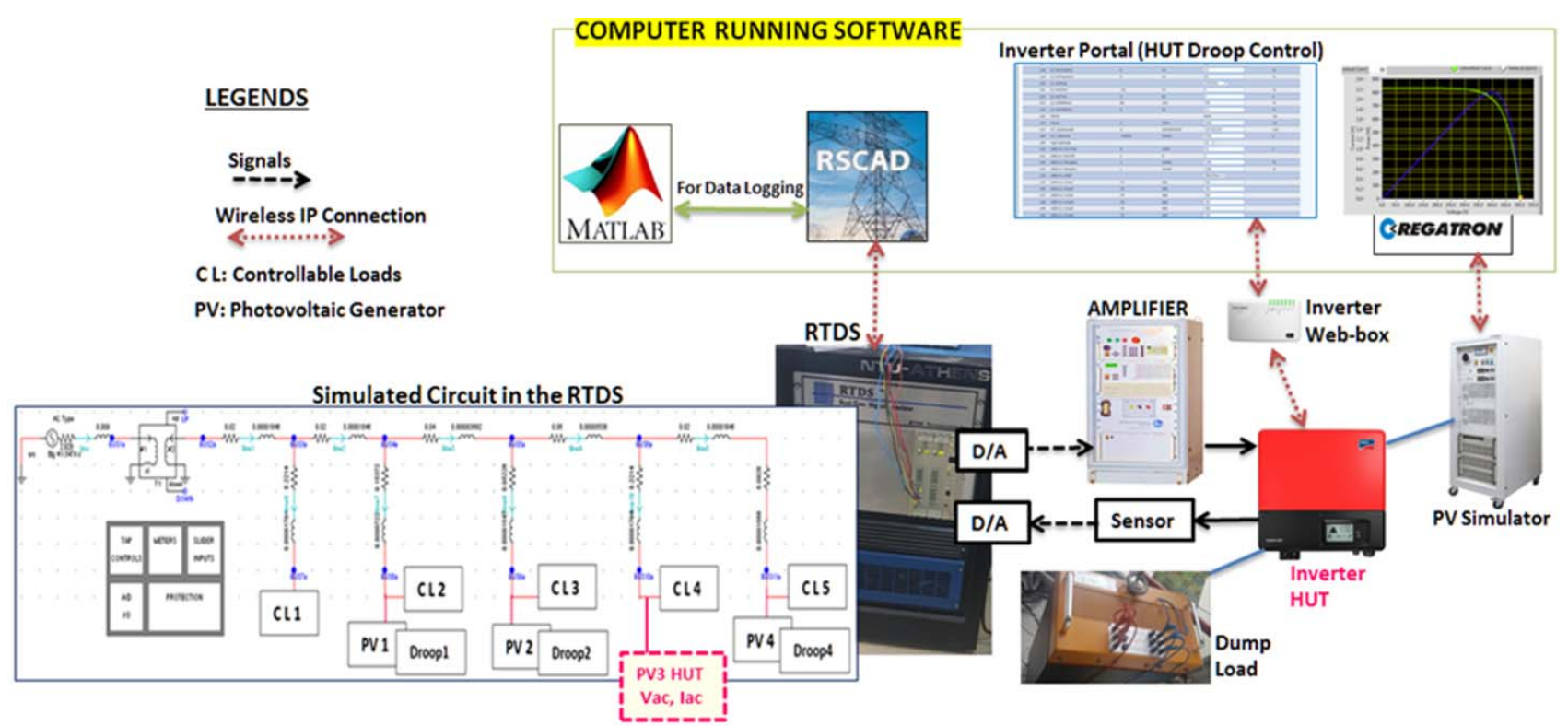

Fig. 6: PHIL Setup with the LV grid network in the RTDS simulator. 


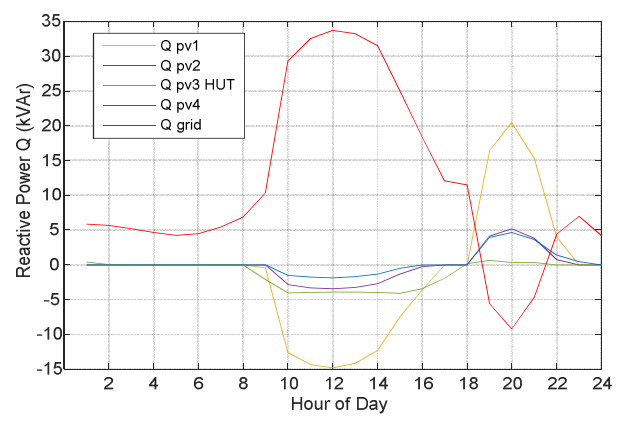

Fig. 9: Reactive Power of PV inverters and Grid with $Q(U)$ droop only

The nominal voltage is $230 \mathrm{~V}(1.0 \mathrm{p} . \mathrm{u})$ but as the voltages go beyond the ideal range which is between $0.98 \mathrm{p} . \mathrm{u}-1.02 \mathrm{p} . \mathrm{u}$ (226V to 235V) as in Fig. 8, the PV inverters perform reactive power compensation in realizing voltage control shown in Fig. 9. The increase in reactive load caused a slight change to the grid's voltage but bigger reactive loads in the microgrid will alter the node voltages and impact $V S e c$ further. The improvement in voltages in Fig. 8 can be seen when compared to the result obtained in Fig. 4 above where the inverter droop controllers were not applied. For instance, the maximum voltage recorded for $V_{P V 1}$ without droop was about $249 \mathrm{~V}$ (8.2\% above nominal voltage) in Fig. 4, but with the inverter droop controllers applied in Fig. 8, the maximum voltage for $V_{P V 1}$ was reduced to approximately $246 \mathrm{~V}(6.9 \%$ above nominal); same situation applies for other voltages. The maximum voltage measured at $V_{P V 3} H U T$ was $243 \mathrm{~V}$ without droop control in Fig. 4 and with droop control applied in Fig. 8 which was reduced to $240 \mathrm{~V}$.

\section{iv. Reactive Power via OLTC and $Q(U)$ Droop Controlled Inverters}

For test cycle iv, both means of ancillary service supply to the grid were implemented paying attention to the response time and contribution of reactive power compensation from the inverter-droop and the OLTC operation.

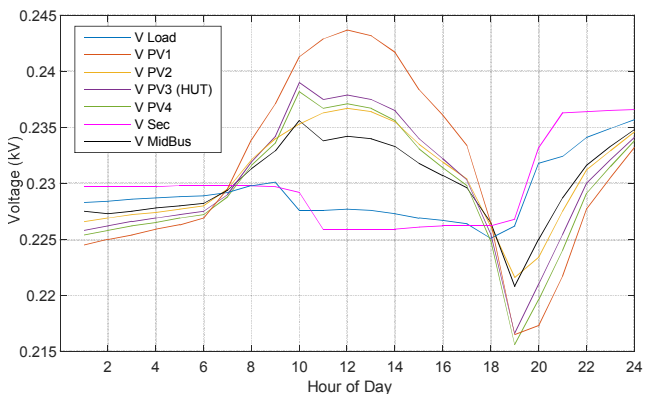

Fig.11: Node Voltages with Droop control and OLTC transformer

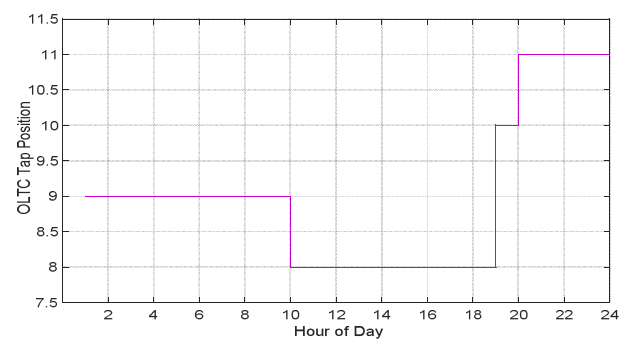

Fig. 12: OLTC Tap Position (OLTC and Q(U) Droop)

Fig. 11 above shows the state of the node voltages; $V$ Sec experienced a drop because of the load requirement and this was further impacted when the load was at peak levels. The inverters' $Q(U)$ controller contributed to reactive power compensation as shown in Fig 14 below, the OLTC was also in operation to realize voltage regulation as the grid condition changes through the day.

By comparing the result in test cycle iv against test cycle ii, it can be seen that the number of OLTC tap switching in Fig. 12 was reduced because of the contribution of reactive power by the PV inverters compared to Fig. 7 that uses OLTC alone for voltage regulation.

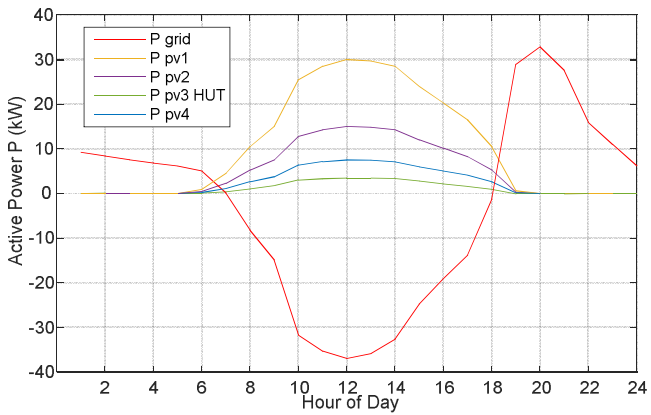

Fig. 13 -Active Power exchange between PV Inverters and main Grid

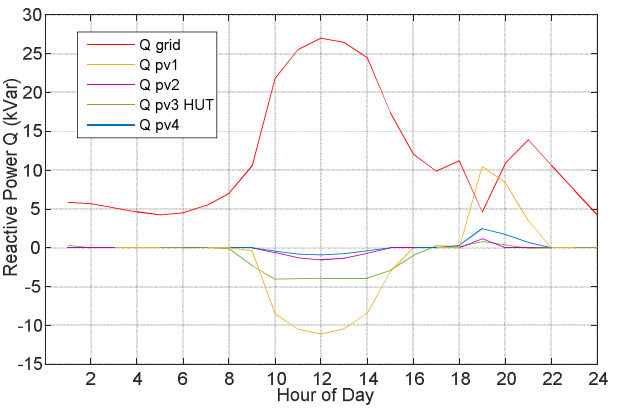

Fig. 14: Reactive Power of PV inverters and Grid (OLTC and Q(U) Droop)

Fig. 13 shows the active power exchanged between the main grid and the microgrid. It can be seen that during higher insolation levels (sunny day), the active power feeds the local loads and the excess from the microgrid flows toward the main grid. As the solar insolation began to decrease toward the end of the day, the main grid became responsible for feeding the local active loads in the microgrid. The PV inverters then had full contribution of reactive power in the grid between 19:00 - 24:00hr because there was no solar insolation for the PV inverters to generate active power as shown in Fig. 13 above.

If energy storage systems are introduced into the microgrid architecture, the excess active power from the PV systems could be stored and later discharged to feed the local loads during the period of low irradiation levels (evenings and night time). In realizing voltage control, the OLTC goes through a time delay before it engages its taps to avoid continuous switching of taps; the inverter droops on the other hand will immediately compensate reactive power once the voltages are out of the ideal set points. In performing voltage regulation through the OLTC alone, the voltage profiles were not as smooth due to the switching of the transformer taps in steps. The voltage profiles when only $\mathrm{Q}(\mathrm{U})$ droop controllers of the inverters are employed were smoother. However, the application of both techniques demonstrates an improved, 
more suitable and cost-effective system overall because there were less OLTC tap changes, i.e. less maintenance needed; OLTC are still in wide use and the cost of the inverters is still relatively costly.

\section{CONCLUSION}

This research has given an insight to resolving the challenges associated with integrating multiple DER sources into the LV grid network; and ancillary service provision. The inverters connected to the PVs have been used as a voltage control tool in providing reactive power using $Q(U)$ droop control; they supported the existing OLTC by reducing the amount of tap switching of the transformer in establishing voltage regulation in the grid. From interfacing a HUT to a real time simulated network in a PHIL setup, testing the modified CIGRE Benchmark Low Voltage Network under realistic conditions was achieved.

\section{ACKNOWLEDGMENT}

This research experiment has been performed using the ERIGrid Research Infrastructure and is part of a project that has received funding from the European Union's Horizon 2020 Research and Innovation Programme under the Grant Agreement No. 654113. The support of the European Research Infrastructure ERIGrid and its partner Smart Grids Research Unit (Smart RUE) - Electric Energy Systems (EES) laboratory at ICCS-NTUA is very much appreciated. The authors acknowledge the support of Prof. Nikos Hatziargyriou.

\section{REFERENCES}

[1] I. Hunter, "Power quality issues a distribution company perspective", IEEE, Power Engineering Journal, 2001, pp 75-80

[2] M.Z. Jacobson, M. Delucchi, "Energy Policy” Journal, Science Direct, 2011, vol.39 pp 1170-1190

[3] W. Yingying, L. Feng, X. Jun, "Prevention control of blackouts in power system based on fault chain and risk theory", IEEE, Int'l Conf on Power System Technology, 2014, ISBN: 978-1-4799-5032-4

[4] T. Lee, S. Hu, S.Yung "Decentralized Control of PV Inverter to Mitigate Voltage Rise in Resistive Feeder", 2018, Int'l Conf. on Green Energy and Smart Grids (GESG 2018), Vol 69, pp 2-11

[5] P. Nahata, S. Mastellone, F.Dorfler, "Decentralized Optimal Projected control of PV inverters in Residential Microgrids", Sc. Direct Journal $-20^{\text {th }}$ IFAC World Congress, pp 6624-6629

[6] X. Hou, Y. Sun, H. Han, Z. Liu, W. Yuan, M. Su, "A fully decentralized control of grid-connected cascaded inverters". IEEE Transc. on Power Delivery. 2018, pp 1

[7] J. O Petinrin, M. Shaaban, "Impact of renewable generation on voltage control in distribution systems" 2016, Sc. Direct Journal on Renewable and Sustainable Energy Reviews, Vol. 65, pp 770-783

[8] J. M. Guerrero, "Microgrids: Integration of distributed energy resources into the smart-grid," in Proc. IEEE Int. Symp. Ind. Electronics, 2010, pp 4281-4414

[9] E. Alegria, T. Brown, E. Minear, and R. H. Lasseter, "CERTS Microgrid Demonstration With Large-Scale Energy Storage and Renewable Generation," IEEE Transactions on Smart Grid, vol. 5, no. 2, pp. 937- 943, Mar. 2014.

[10] F. D. Kanellos, A. I. Tsouchnikas, and N. D. Hatziargyriou, "Microgrid Simulation during Grid-Connected and Islanded Mode of Operation”, IEEE Int. Conf. Power Sys. Transients (IPST’05), 2005.

[11] X. Guobin, P. Moulema, Y. Wei "Integrating distributed energy resources in smart grid: Modelling and analysis" IEEE Energytech Conference, 2013, pp 1-5
[12] J. Rocabert, A. Luna, F. Blaabjerg, and P. Rodriguez, "Control of power converters in ac micro-grids", IEEE Trans. on Power Electronics, 2012, vol. 27, no. 11, pp. 4734-4749

[13] R. Farooq, M. Laeeq, A. Massab, A. Syeda, "Smart DC micro-grids: Modeling and power flow analysis of a DC Micro-grid for off-grid and weak-grid connected communities", (2014), IEEE PES-Asia Pacific, Power and Energy Engineering Conf. (APPEEC), pp 1-6

[14] S. Oyegoke, Y.T. Habtay, "Contribution of inverter based photovoltaic generators to power quality at low voltage", IEEE, 50th Int'l Universities Power Engineering Conf (UPEC), 2015, pp 1-6

[15] Zhang, Y. Yang, C. Ji, W. Wei, Y. Chen, C. Meng, Z. Jin, G. Zhang, "Power management strategy research for DC micro-grid with hybrid storage system",(2015) IEEE Int'l Conf on DC Micro-grids (ICDCM), pp62-68

[16] Erik de Jong, et al "European White Book on Real-Time Power Hardware-in-the-Loop testing", 2012, pp 1-46, DERlab Report No. R005.0, ISBN: 978-3-943517-01-9

[17] M. Steurer, F. Bogdan, W. Ren, M. Sloderbeck, S. Woodruff "Controller and Power Hardware-In-Loop Methods for Accelerating Renewable Energy Integration", 2007, IEEE Power Engineering Society General Meeting

[18] M. Maniatopoulos, D. Lagos, P. Kotsampopoulos, N. Hatziargyriou, "Combined control and power hardware in-the-loop simulation for testing smart grid control algorithms", IET Generation, Transmission \& Distribution, 2017, Vol: 11, Iss: 12, pp. $3009-3018$

[19] R, Brandi, M. Calin, T. Degner, 'Power Hardware-in-the-Loop setup for Power System Stability Analyses', IET 24th Int'l Conference \& Exhibition on Electricity Distribution (CIRED), pp 387-390.

[20] T. S. Ustun, H. Konish, J. Hashimoto, K. Otani, "Hardware-in-the-loop simulation based Testing of power conditioning systems", 2018, IEEE International Conference on Industrial Electronics for Sustainable Energy Systems (IESES), pp $546-551$

[21] S. Lentijo, S. D'Arco, and A. Monti, "Comparing the dynamic performances of power hardware-inthe-loop interfaces," IEEE Trans. Industrial Electronics, vol. 57, no. 4, pp. 1195-1207, 2010.

[22] B. Ojaghloo, G.B. Gharehpetian, "Power Hardware in The Loop Realization, Control and Simulation of Synchronous Generator Using Three Phase VSI for Microgrid Studies", 2017, Int'l Conf. on Renewable Energies and Power Quality, pp $108-113$.

[23] Z. Taylor, H. Akhavan-Hejazi, H. Mohsenian-Rad, "Power Hardwarein-Loop Simulation of Grid-connected Battery Systems with Reactive Power Control Capability", 2017, North American Power Symposium (NAPS), ISBN: 978-1-5386-2699-3

[24] R. Wei, M. Steurer, and T. L. Baldwin, "Improve the Stability and the Accuracy of Power Hardware-in-the-Loop Simulation by Selecting Appropriate Interface Algorithms," 2008, IEEE Transactions on Industry Applications, vol. 44, pp. 1286-1294.

[25] Z. Zhang, L. Fickert, "Power Hardware-in-the-Loop testing for the Inverter based Distributed Power Source", 2016，14th Symposium on Energy Innovation, Vol 10, Issue 1

[26] P. Kotsampopoulos, F. Lehfuss, G. Lauss, B. Bletterie, N. Hatziargyriou, "The Limitations of Digital Simulation and the advantages of PHIL Testing in Studying Distributed Generation Provision of Ancillary Services," IEEE Trans on Indus Electronics, Sept 2015, vol 62, no 9, pp.5502 -5515

[27] U.Tayab, M. Roslan, L. Hwai, M. Kashif, "A review of droop control techniques for microgrid", 2017, Sc. Direct - Elsevier Jornal on Renewable and Sustainable Energy Reviews, Vol 76, pp 717- 727.

[28] S. Manusur, M. Marei, A. Sattar, "Droop based Control Strategy for a Microgrid", 2016, Global Journal of Researches in Engineering: Elect and Electr Engr. Vol. 16 Iss. 7 Ver 1.0, pp 2249-4596

[29] P. Estefanía, G. Asier, A. Jon, k. Iñigo, M. Iñigo, "General aspects, hierarchical controls and droop methods in microgrids: A review", Renewable and Sustainable Energy Reviews 17 (2013)147-159.

[30] S. Papathanassiou, N. Hatziargyriou, K. Strunz, 'A benchmark low voltage microgrid'. CIGRé Symp. 'Power systems with Dispersed Generation: Technologies, Impacts on Development, Operation and Performances', Athens, Greece, April 2005

[31] F. Andrén, et al, "On the Stability of Local Voltage Control in Distribution Networks With a High Penetration of Inverter-Based Generation”, 2015, IEEE Trans on Industrial Elect, Vol 62, Iss 4, pp $2519-2529$ 